\title{
Bonelike Apatite Formation on Ethylene-Vinyl Alcohol Copolymer Modified with a Silane Coupling Agent and Titania Solution
}

\author{
Ayako OYANE, Masakazu KAWASHITA, Tadashi KOKUBO, Masahiko MINODA,* \\ Takeaki MIYAMOTO** and Takashi NAKAMURA*** \\ Department of Material Chemistry, Graduate School of Engineering, Kyoto University, Yoshida, Sakyo-ku, Kyoto-shi 606-8501 \\ *Department of Chemistry and Materials Technology, Faculty of Engineering and Design, Kyoto Institute of Technology, \\ Matsugasaki, Sakyo-ku, Kyoto-shi 606-8585 \\ **Matsue National College of Technology, 14-4, Nishiikuma, Matsue-shi 690-8518 \\ ***Department of Orthopaedic Surgery, Graduate School of Medicine, Kyoto University, Shogoin, Sakyo-ku, Kyoto-shi $606-8507$
}

\section{シランカップリング剤及びチタニア溶液で処理したエチレンービニルアルコール 共重合体上での骨類似アパタイト形成}

\author{
大矢根綾子 $\cdot$ 川下将一－小久保 正·箕田雅彦*·宮本武明**·中村孝志*** \\ 京都大学大学院工学研究科材料化学専攻, 606-8501 京都市左京区吉田本町 \\ *京都工芸繊維大学工芸学部物質工学科，606-8585 京都市左京区松ヶ崎御所街道町 \\ **松江工業高等専門学校, 690-8518 松江市西生馬町 14-4 \\ ***京都大学大学院医学研究科外科系專攻, 606-8507 京都市左京区聖護院川原町
}

\begin{abstract}
The surface of an ethylene-vinyl alcohol copolymer (EVOH) was modified with Ti-OH groups by a silane coupling treatment followed by treatment with a titania solution. The arrangement of the Ti-OH groups formed on $\mathrm{EVOH}$ was changed from amorphous into anatase structure by a subsequent $\mathrm{HCl}$ solution treatment. Bonelike nanoapatite was successfully formed on the surface-modified EVOH even in a form of fibers as well as plates within $2 \mathrm{~d}$ at $36.5^{\circ} \mathrm{C}$ in a simulated body fluid (SBF) with ion concentrations approximately equal to those of human blood plasma. The resultant nanoapatite-polymer fiber composite was similar to that of natural bone in its structure where apatite nanocrystals are deposited on fine organic fibers constituting a composite. Therefore, if the present surface modification can be applied to a three-dimensional fabric with a structure similar to the collagen fibers of natural bone, a composite with an analogous structure to that of natural bone would be obtained. The resultant composite is expected to exhibit mechanical properties analogous to those of natural bone, as well as bone-bonding ability, and hence be truly useful as a new bone substitute.

[Received October 31, 2001; Accepted March 25, 2002]
\end{abstract}

Key-words : Apatite, Ethylene-vinyl alcohol copolymer, Anatase, Ti-OH groups, Biomimetic method, Simulated body fluid

\section{Introduction}

Natural bone is a composite in which inorganic apatite nanocrystals are deposited on organic collagen fibers woven into a three-dimensional structure. ${ }^{1)}$ If synthetic organic polymer fibers are fabricated into a three-dimensional structure similar to that of the collagen fibers in natural bone, and bonelike apatite is deposited on their surfaces, a composite with an analogous structure to that of natural bone could be obtained. If the resultant composites exhibit analogous mechanical properties to those of natural bone, ${ }^{2)}$ and have bone-bonding ability through the bonelike apatite layer on its surface, ${ }^{3), 4)}$ they can be truly useful as a bone substitute.

Although various attempts to prepare such a composite have been made, none of them have successfully produced a composite with bone-bonding ability and mechanical properties analogous to those of natural bone. ${ }^{5)-8)}$ For example, Shikinami and Kawarada prepared a three-dimensional polyethylene fabric, spray-coated with pure hydroxyapatite powder. ${ }^{7)}$ In this process, however, pure hydroxyapatite powder was physically deposited only on the outer surface of the fabric. Therefore, the stiffness of this fabric was not sufficient to allow the fabric to be used as a bone substitute under load-bearing conditions. Furthermore, pure hydroxyapatite is rather different from bone apatite in its composition and structure, ${ }^{9)}$ and hence requires a long period to bond to the bone.10) In order to obtain bonelike apatite, apatite must be formed in a simulated body fluid (SBF) ${ }^{11}$ ) with ion concentrations approximately equal to those of human blood plasma. ${ }^{12)}$

The present authors have previously attempted to prepare the above-mentioned composite by a biomimetic process, ${ }^{13), 14)}$ in which the surface of a polymeric material was modified with functional groups effective in inducing apatite nucleation, and then soaked in SBF. Si-OH groups were used as the functional groups effective in inducing apatite nucleation, since a pure silica gel rich in $\mathrm{Si}-\mathrm{OH}$ groups forms bonelike apatite on its surface in SBF. ${ }^{15)}$-20) An ethylene-vinyl alcohol copolymer $(\mathrm{EVOH}),{ }^{21)}$ with high mechanical strength and good biocompatibility, was used as the polymeric material. The surface modification of EVOH with $\mathrm{Si}-\mathrm{OH}$ groups was carried out by treatment with a silane coupling agent, namely, 3-isocyanatopropyltriethoxysilane $\left(\mathrm{OCN}\left(\mathrm{CH}_{2}\right)_{3} \mathrm{Si}\left(\mathrm{OC}_{2} \mathrm{H}_{5}\right)_{3}\right.$; IPTS $)$, and a calcium silicate solution. The surface-modified specimen formed apatite on its surface in SBF within $2 \mathrm{~d}$ at $36.5^{\circ} \mathrm{C}$. In this process, however, a calcium-containing silica gel layer formed on the specimen is liable to dissolve into the surrounding fluid over a long period.

Recently, it has been shown that not only $\mathrm{Si}-\mathrm{OH}$, but also other functional groups such as $\mathrm{Ti}-\mathrm{OH},{ }^{22)-24)} \mathrm{Ta}-\mathrm{OH},{ }^{25}$ ) $\mathrm{Nb}-\mathrm{OH}^{26)}$ and $\mathrm{Zr}-\mathrm{OH}^{27)}$ are effective for apatite nucleation in SBF. Among them, Ti-OH groups in a titania gel with an anatase structure have been reported to be remarkably effective in inducing apatite nucleation in SBF. ${ }^{24)}$ In addi- 
tion, a titania gel would be stable in the body environment for a long period, since the solubility of a titania gel is much lower than that of a silica gel. ${ }^{28}$,

In the present study, the surfaces of an $\mathrm{EVOH}$ plate and a knitted yarn of EVOH fibers were modified with $\mathrm{Ti}-\mathrm{OH}$ groups by treatment with a silane coupling agent and a titania solution. The arrangement of the $\mathrm{Ti}-\mathrm{OH}$ groups formed on EVOH was changed into anatase structure by subsequent $\mathrm{HCl}$ solution treatment. The apatite-forming ability of the surface-modified specimen was examined in SBF.

\section{Experimental}

\subsection{Preparation of specimens}

An EVOH plate, $1 \mathrm{~mm}$ in thickness, was prepared by hotpressing pellets of EVOH with quoted ethylene content of $32 \mathrm{~mol} \%$, generously supplied by Kuraray Co., Ltd., Kurashiki, Japan, at $200^{\circ} \mathrm{C}$. The EVOH plate was cut into square pieces, $10 \times 10 \mathrm{~mm}^{2}$ in size, and then abraded with a \#400 diamond pad. Knitted yarn of EVOH made of 420 fibers with a diameter of $3 \mu \mathrm{m}$ and with quoted ethylene content of $32 \mathrm{~mol} \%$, was generously supplied by Kuraray Co., Ltd., Kurashiki, Japan. A specimen of the knitted yarn of EVOH fibers was cut into square pieces, $10 \times 10 \mathrm{~mm}^{2}$ in size. Specimens of both the EVOH plate and the knitted yarn of EVOH fibers were ultrasonically washed with acetone and 2-propanol, and then dried at $100^{\circ} \mathrm{C}$ under vacuum for $24 \mathrm{~h}$.

\subsection{Silane coupling treatment}

The specimen was soaked in a solution with a mass ratio of IPTS (Chisso Co., Tokyo): toluene (Wako Pure Chemical Industries Ltd., Osaka): dibutyltin dilaurate (Nacalai Tesque Inc., Kyoto) of $1.0: 1.0: 0.005$ at $50^{\circ} \mathrm{C}$ for $6 \mathrm{~h}$ in a nitrogen atmosphere. The specimen was removed from the solution, washed sequentially with tetrahydrofuran, 2-propanol and toluene, and then dried at room temperature for $24 \mathrm{~h}$ under vacuum (denoted as EI). The specimen was subsequently soaked in $0.05 \mathrm{M} \mathrm{HCl}$ aqueous solution at $40^{\circ} \mathrm{C}$ for $12 \mathrm{~h}$, washed with ultra-pure water, and then dried at room temperature for $24 \mathrm{~h}$ under vacuum (denoted as $\mathrm{EIH}$.

\subsection{Titania solution treatment}

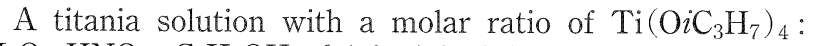
$\mathrm{H}_{2} \mathrm{O}: \mathrm{HNO}_{3}: \mathrm{C}_{2} \mathrm{H}_{5} \mathrm{OH}$ of $1.0: 1.0: 0.1: 9.25$ was prepared by stirring a mixture of $\mathrm{Ti}\left(\mathrm{O} i \mathrm{C}_{3} \mathrm{H}_{7}\right)_{4}$, ultra-pure water, ethyl alcohol, and 60 mass $\% \mathrm{HNO}_{3}$ aqueous solution (Nacalai Tesque Inc., Kyoto) at $0^{\circ} \mathrm{C}$. The specimen of $\mathrm{EIH}$ was soaked in the titania solution at $25^{\circ} \mathrm{C}$ for $24 \mathrm{~h}$, withdrawn from the solution at a rate of $2 \mathrm{~cm} / \mathrm{min}$, and then heated at $100^{\circ} \mathrm{C}$ for $10 \mathrm{~min}$. The specimen was then dipped again into the solution, immediately withdrawn at the same rate, and then heated at $100^{\circ} \mathrm{C}$ for $10 \mathrm{~min}$. After this dipping, withdrawing and heating process was repeated four times, the specimen was finally heated at $100^{\circ} \mathrm{C}$ for $24 \mathrm{~h}$ (denoted as EIHT).

\section{$2.4 \mathrm{HCl}$ solution treatment}

The specimen of EIHT was subsequently treated with ultra-pure water or $\mathrm{HCl}$ aqueous solutions at various concentrations up to $1.00 \mathrm{M}$ at $80^{\circ} \mathrm{C}$ for various periods up to $8 \mathrm{~d}$. The specimen, removed from the solution, was washed with ultra-pure water at $40^{\circ} \mathrm{C}$ for $12 \mathrm{~h}$.

\subsection{Soaking in SBF}

The surface-modified specimen was soaked in $30 \mathrm{ml}$ of $\mathrm{SBF}^{11)}$ at $\mathrm{pH} 7.40$ and with ion concentrations $\left(\mathrm{Na}^{+} 142.0\right.$, $\mathrm{K}^{+} 5.0, \mathrm{Mg}^{2+} 1.5, \mathrm{Ca}^{2+} 2.5, \mathrm{Cl}^{-} 147.8, \mathrm{HCO}_{3}-4.2, \mathrm{HPO}_{4}{ }^{2-}$ $1.0, \mathrm{SO}_{4}{ }^{2-} 0.5 \mathrm{mM}$ ) approximately equal to those of human blood plasma at $36.5^{\circ} \mathrm{C}$ for various periods up to $14 \mathrm{~d}$. The SBF was prepared by dissolving reagent-grade chemicals of $\mathrm{NaCl}, \mathrm{NaHCO}_{3}, \mathrm{KCl}, \mathrm{K}_{2} \mathrm{HPO}_{4} \cdot 3 \mathrm{H}_{2} \mathrm{O}, \mathrm{MgCl}_{2} \cdot 6 \mathrm{H}_{2} \mathrm{O}, \mathrm{CaCl}_{2}$, and $\mathrm{Na}_{2} \mathrm{SO}_{4}$ (Nacalai Tesque Inc., Kyoto) in ultra-pure water, and buffering at $\mathrm{pH} 7.40$ with tris (hydroxymethyl) aminomethane $\left(\left(\mathrm{CH}_{2} \mathrm{OH}\right)_{3} \mathrm{CNH}_{2}\right)$ and $1.00 \mathrm{M} \mathrm{HCl}$ aqueous solution (Nacalai Tesque Inc., Kyoto) at $36.5^{\circ} \mathrm{C} .{ }^{29)}$ After a given soaking period, the specimen was removed from the fluid, gently washed with ultra-pure water, and then dried at room temperature for $24 \mathrm{~h}$.

\subsection{Surface characterization}

The surface structures of the specimens were examined by using an X-ray photoelectron spectrometer (XPS; MT-5500, ULVAC-PHI Co., Ltd., Chigasaki) with Mg K $\alpha$ radiation, a thin-film X-ray diffractometer (TF-XRD; RINT2500, Rigaku Co., Tokyo) with $\mathrm{Cu} \mathrm{K} \alpha$ radiation, and a field emission scanning electron microscope (FE-SEM: S-4700, Hitachi Ltd., Tokyo). The photoelectron take-off angle was set at $45^{\circ}$ for XPS, and the glancing angle was set at $1^{\circ}$ against the direction of the incident beam with a thin film attachment for TF-XRD.

\section{Results}

Survey and $\mathrm{C}_{1 \mathrm{~s}}$ XPS spectra are shown in Fig. 1 (a) and (b), respectively, for the surfaces of the EVOH, EI and EIH plates. After the silane coupling treatment (EI), peaks ascribed to $\mathrm{N}_{1 \mathrm{~s}}, \mathrm{Si}_{2 \mathrm{~s}}$ and $\mathrm{Si}_{2 \mathrm{p}}$ appeared on the survey spectra (see Fig. 1(a)). On the $\mathrm{C}_{1 \mathrm{~s}}$ spectra in Fig. 1(b), a peak ascribed to $\mathrm{C}=\mathrm{O}$ appeared after the silane coupling treatment (EI). These results indicate that the surface of the $\mathrm{EVOH}$ plate reacted with an isocyanato group of IPTS during the silane coupling treatment, causing $\mathrm{Si}-\mathrm{OC}_{2} \mathrm{H}_{5}$ groups to be introduced onto the EVOH surface as shown in the following equation, ${ }^{30)}$

$$
\begin{aligned}
& \mathrm{R}-\mathrm{OH}+\mathrm{IPTS} \\
& \longrightarrow \mathrm{R}-\mathrm{OC}(\mathrm{O}) \mathrm{NH}\left(\mathrm{CH}_{2}\right)_{3} \mathrm{Si}\left(\mathrm{OC}_{2} \mathrm{H}_{5}\right)_{3}
\end{aligned}
$$

where $R$ represents a carbon atom on the EVOH surface. When the EI plate was subsequently treated with an $\mathrm{HCl}$ solution (EIH), a shoulder ascribed to $\mathrm{C}-\mathrm{O}$ disappeared in the $\mathrm{C}_{1 \mathrm{~s}}$ spectra (see Fig. 1(b)). This result indicates that $\mathrm{Si}-\mathrm{OC}_{2} \mathrm{H}_{5}$ groups on the specimen were hydrolyzed into $\mathrm{Si}-\mathrm{OH}$ groups due to the catalytic effect of $\mathrm{HCl}$.

Figure 2 shows XPS survey spectra (a), and TF-XRD patterns (b), of surfaces of the EIHT plates, untreated and treated with ultra-pure water or $\mathrm{HCl}$ solutions with various concentrations up to $1.00 \mathrm{M}$ for $5 \mathrm{~d}$. On the XPS spectra in Fig. 2(a), peaks ascribed to $\mathrm{Ti}_{2 \mathrm{p}}$ and $\mathrm{Ti}_{3 \mathrm{p}}$ were observed for the untreated EIHT plate, i.e., the specimen as treated with a titania solution. It can be seen from this result that a titania layer was successfully formed on the specimen after the titania solution treatment. The peak intensity of $\mathrm{C}_{1 \mathrm{~s}}$ in the spectra decreased with increasing $\mathrm{HCl}$ concentration up to 0.10 $\mathrm{M}$ in subsequent treatment with ultra-pure water or $\mathrm{HCl}$ solutions. This indicates that the number of alkoxy groups in the titania layer decreased with increasing $\mathrm{HCl}$ concentration up to $0.10 \mathrm{M}$ in the treatment. The decrease in the number of alkoxy groups is attributed to a hydrolysis reaction of alkoxy groups in the titania layer to form Ti-OH groups, catalyzed by $\mathrm{HCl}$. For the specimen treated with $1.00 \mathrm{M}$ $\mathrm{HCl}$ solution, peaks ascribed to $\mathrm{Ti}_{2 \mathrm{p}}$ and $\mathrm{Ti}_{3 \mathrm{p}}$ were not observed, whereas those ascribed to $\mathrm{N}_{1 \mathrm{~s}}, \mathrm{Si}_{2 \mathrm{~s}}$ and $\mathrm{Si}_{2 \mathrm{p}}$ were observed, giving a spectrum quite similar to that of the EIH plate, i.e., the specimen before the titania solution treatment (see Fig. 1(a)). This result suggests that the titania layer on the specimen dissolved into $1.00 \mathrm{M} \mathrm{HCl}$ solution by the $\mathrm{HCl}$ solution treatment.

On the TF-XRD patterns in Fig. 2 (b), a peak ascribed to anatase was detected for the EIHT plate treated with ultrapure water, $0.01 \mathrm{M}$ or $0.10 \mathrm{M} \mathrm{HCl}$ solution for $5 \mathrm{~d}$, but not detected for the untreated EIHT plate. This can be interpreted as the structure of the titania layer on the specimen being transformed from an amorphous form into anatase by 

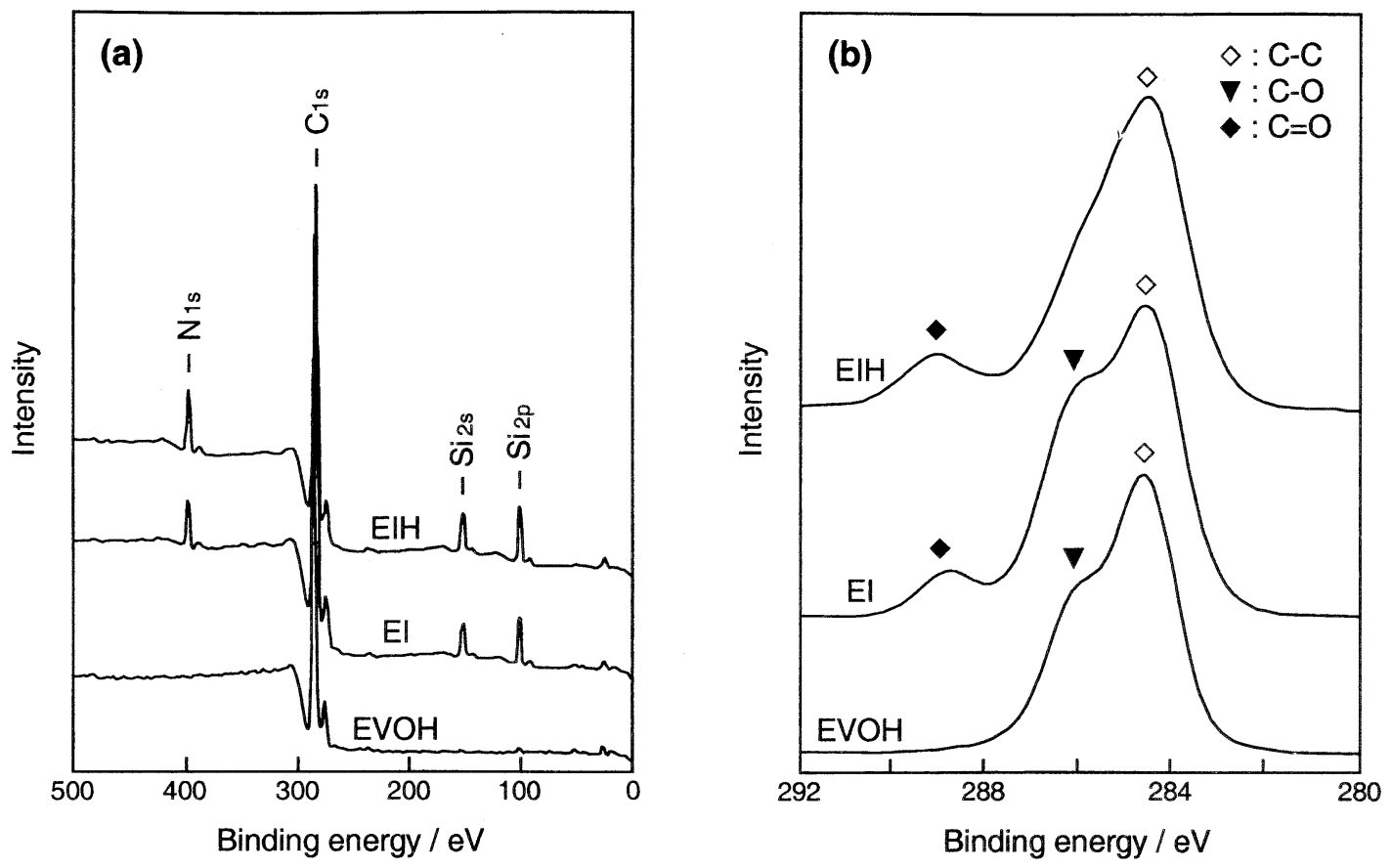

Fig. 1. Survey (a) and $\mathrm{C}_{1 \mathrm{~s}}$ (b) XPS spectra of surfaces of the EVOH, EI and EIH plates.
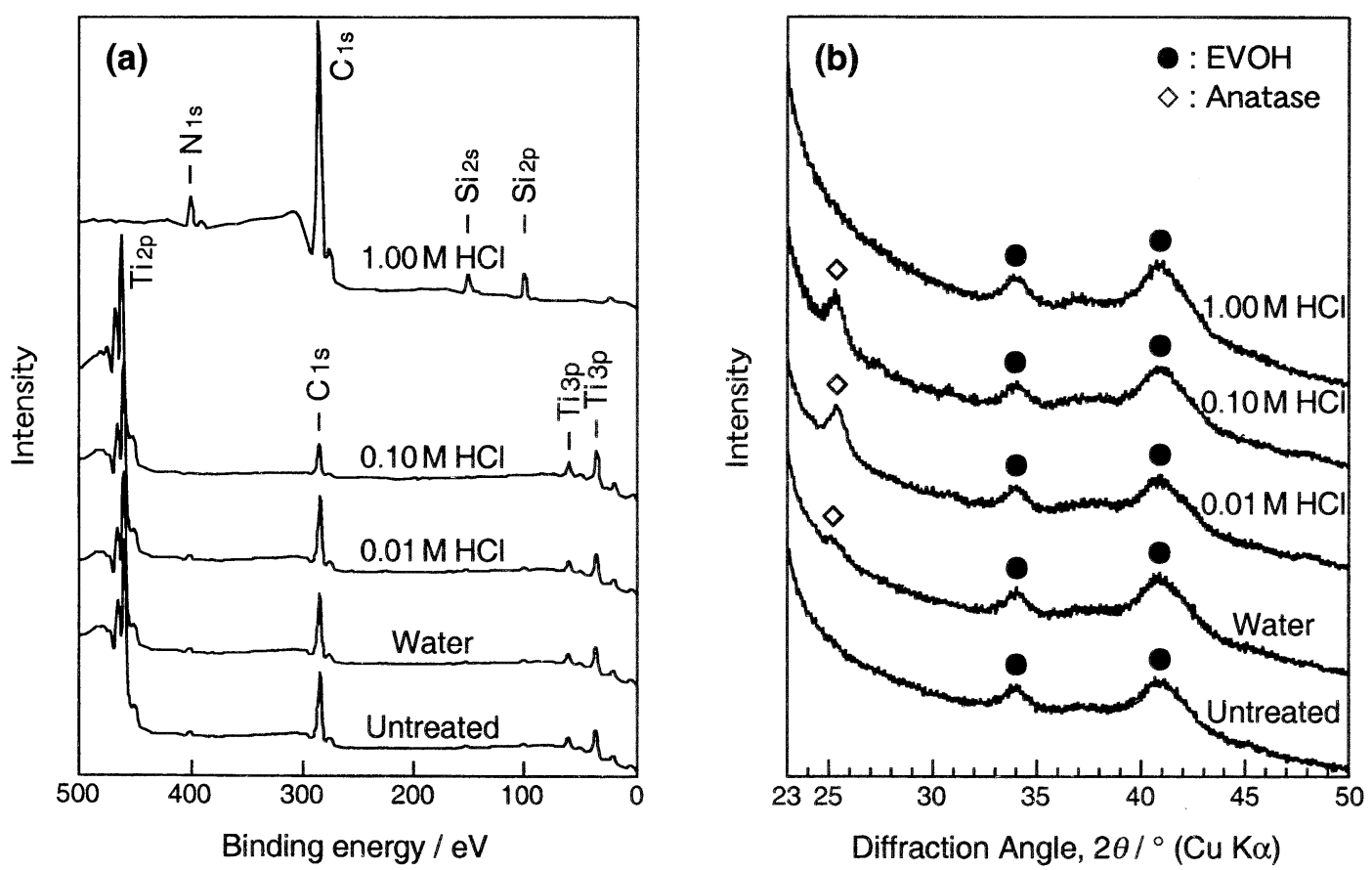

Fig. 2. XPS survey spectra (a) and TF-XRD patterns (b) of surfaces of the EIHT plates, untreated and treated with ultra-pure water or $\mathrm{HCl}$ solutions with various concentrations up to $1.00 \mathrm{M}$ for $5 \mathrm{~d}$.

treatment with ultra-pure water or $\mathrm{HCl}$ solutions. The peak intensity of anatase increased with increasing $\mathrm{HCl}$ concentration up to $0.10 \mathrm{M}$ in the treatment. This indicates that the transformation of amorphous titania into anatase was promoted by $\mathrm{HCl}$ through its catalytic effect on a hydrolysis reaction of alkoxy groups to form Ti-OH groups in the titania layer. However, no peak ascribed to anatase was observed for the specimen treated with $1.00 \mathrm{M} \mathrm{HCl}$ solution.
This might be because the titania layer on the specimen dissolved into $1.00 \mathrm{M} \mathrm{HCl}$ solution by the $\mathrm{HCl}$ solution treatment, as noted above from the XPS result.

Figure 3 shows TF-XRD patterns of surfaces of the EIHT plates, untreated and treated with ultra-pure water or $\mathrm{HCl}$ solutions with various concentrations up to $1.00 \mathrm{M}$ for $5 \mathrm{~d}$, and subsequently soaked in SBF for $14 \mathrm{~d}$. The untreated EIHT plate and the EIHT plate treated with ultra-pure 
water or $1.00 \mathrm{M} \mathrm{HCl}$ solution, did not form apatite on their surfaces in SBF even after $14 \mathrm{~d}$. In contrast, the EIHT plate treated with $0.01 \mathrm{M}$ or $0.10 \mathrm{M} \mathrm{HCl}$ solution formed apatite on its surface within $14 \mathrm{~d}$. The peak intensity of apatite was higher for the specimen treated with $0.10 \mathrm{M} \mathrm{HCl}$ solution than that treated with $0.01 \mathrm{M} \mathrm{HCl}$ solution.

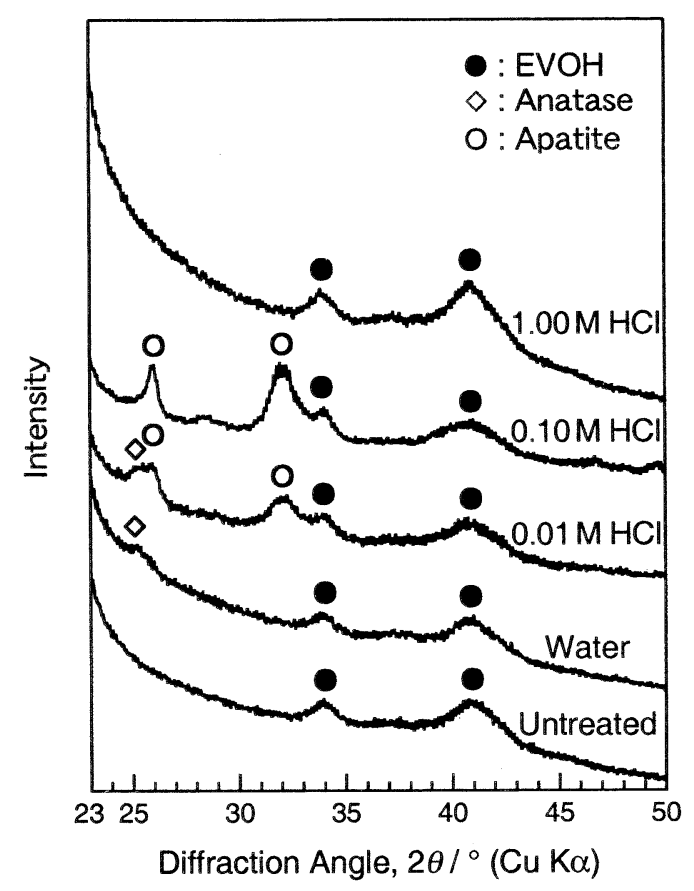

Fig. 3. TF-XRD patterns of surfaces of the EIHT plates, untreat ed and treated with ultra-pure water or $\mathrm{HCl}$ solutions with various concentrations up to $1.00 \mathrm{M}$ for $5 \mathrm{~d}$, and subsequently soaked in SBF for $14 \mathrm{~d}$.

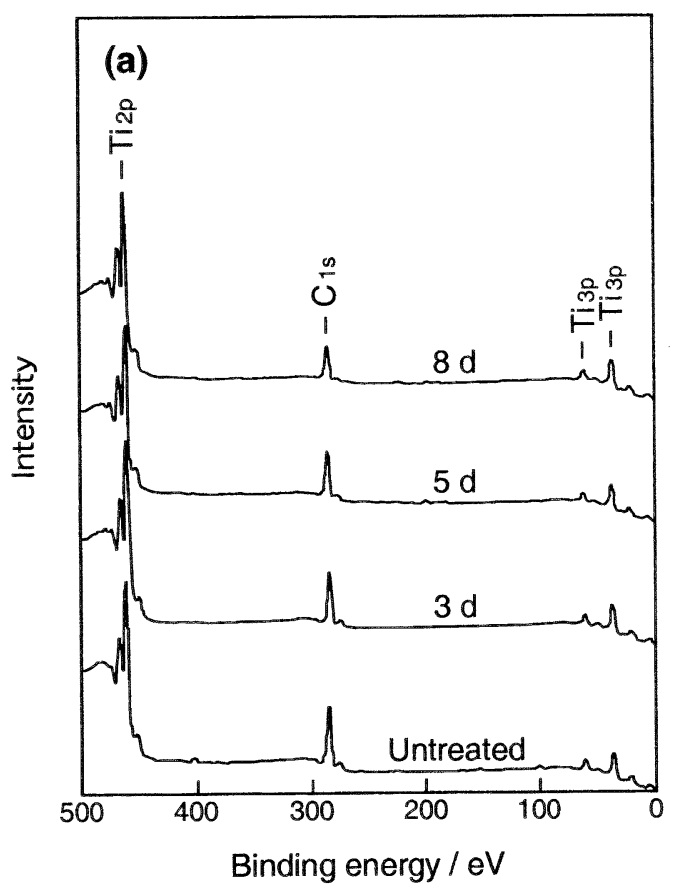

XPS survey spectra (a), and TF-XRD patterns (b), of surfaces of the EIHT plates, untreated and treated with 0.10 $\mathrm{M} \mathrm{HCl}$ solution for various periods up to $8 \mathrm{~d}$, are shown in Fig. 4. On the XPS spectra in Fig. 4(a), peaks ascribed to $\mathrm{Ti}_{2 \mathrm{p}}$ and $\mathrm{Ti}_{3 \mathrm{p}}$ were observed for all of the specimens. The peak intensity of $\mathrm{C}_{1 \mathrm{~s}}$ on the spectra decreased with increasing period of $\mathrm{HCl}$ solution treatment up to $8 \mathrm{~d}$, indicating that the number of alkoxy groups in the titania layer decreased with increasing period of treatment. This is because the alkoxy groups in the titania layer were hydrolyzed into $\mathrm{Ti}-\mathrm{OH}$ groups by the $\mathrm{HCl}$ solution treatment.

On the TF-XRD patterns in Fig. 4(b), the peak intensity of anatase increased with increasing period of $\mathrm{HCl}$ solution treatment up to $8 \mathrm{~d}$. This indicates that the amount of deposited anatase on the specimen increased with increasing period of $\mathrm{HCl}$ solution treatment up to $8 \mathrm{~d}$.

Figure 5 shows TF-XRD patterns of surfaces of the EIHT plates, untreated and treated with $0.10 \mathrm{M} \mathrm{HCl}$ solution for various periods up to $8 \mathrm{~d}$, and subsequently soaked in SBF for $2 \mathrm{~d}(\mathrm{a}), 7 \mathrm{~d}(\mathrm{~b})$, or $14 \mathrm{~d}$ (c). The EIHT plates treated with $0.10 \mathrm{M} \mathrm{HCl}$ solution for 3,5 and $8 \mathrm{~d}$ formed apatite on their surfaces within 7,2 and $2 \mathrm{~d}$, respectively. Among the specimens soaked in SBF for $2 \mathrm{~d}$, the specimen treated for $8 \mathrm{~d}$ gave a higher peak intensity of apatite than the specimen treated for $5 \mathrm{~d}$ (see Fig. $5(\mathrm{a})$ ).

FE-SEM photographs of surfaces of the plates of EVOH (a), EIH (b), EIHT treated with $0.10 \mathrm{M} \mathrm{HCl}$ solution for $8 \mathrm{~d}$ (c), and EIHT treated with $0.10 \mathrm{M} \mathrm{HCl}$ solution for $8 \mathrm{~d}$ and then soaked in SBF for $2 \mathrm{~d}$ (d), are shown in Fig. 6. The surface morphologies of the EVOH and EIH plates were almost the same (see Fig. 6(a) and (b)). This is attributed to the extremely thin IPTS layer formed on the EIH plate. ${ }^{13), 14)}$ After subsequent treatment with titania and $\mathrm{HCl}$ solutions, a new layer was formed on the surface of the specimen (see Fig. 6 (c)). This layer should be a titania layer with an anatase structure, according to the XPS and TF-XRD results shown in Fig. 4. When this specimen was subsequently soaked in SBF for $2 \mathrm{~d}$, a layer consisting of

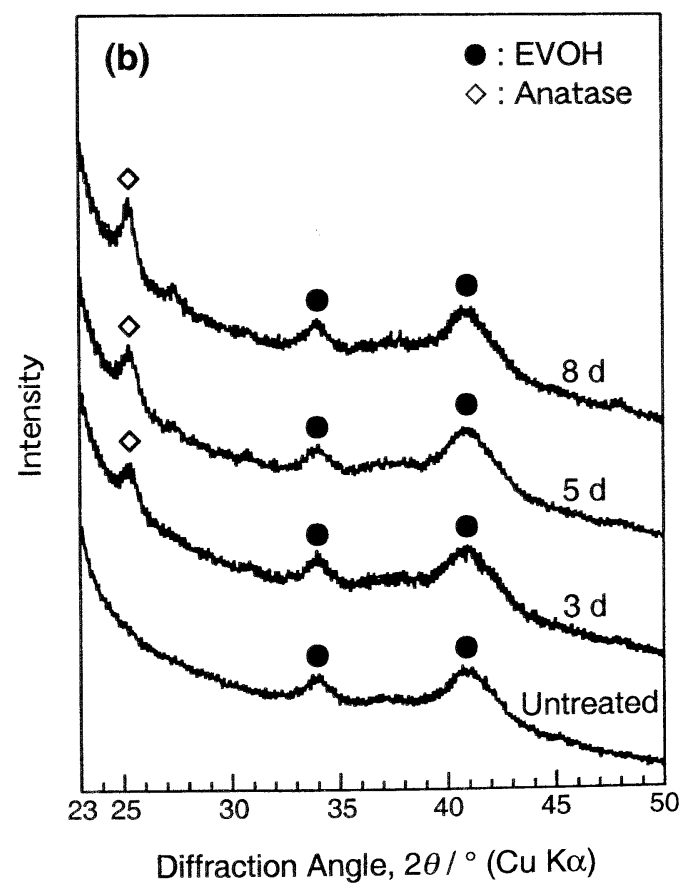

Fig. 4. XPS survey spectra (a) and TF-XRD patterns (b) of surfaces of the EIHT plates, untreated and treated with $0.10 \mathrm{M} \mathrm{HCl} \mathrm{solution}$ for various periods up to $8 \mathrm{~d}$. 

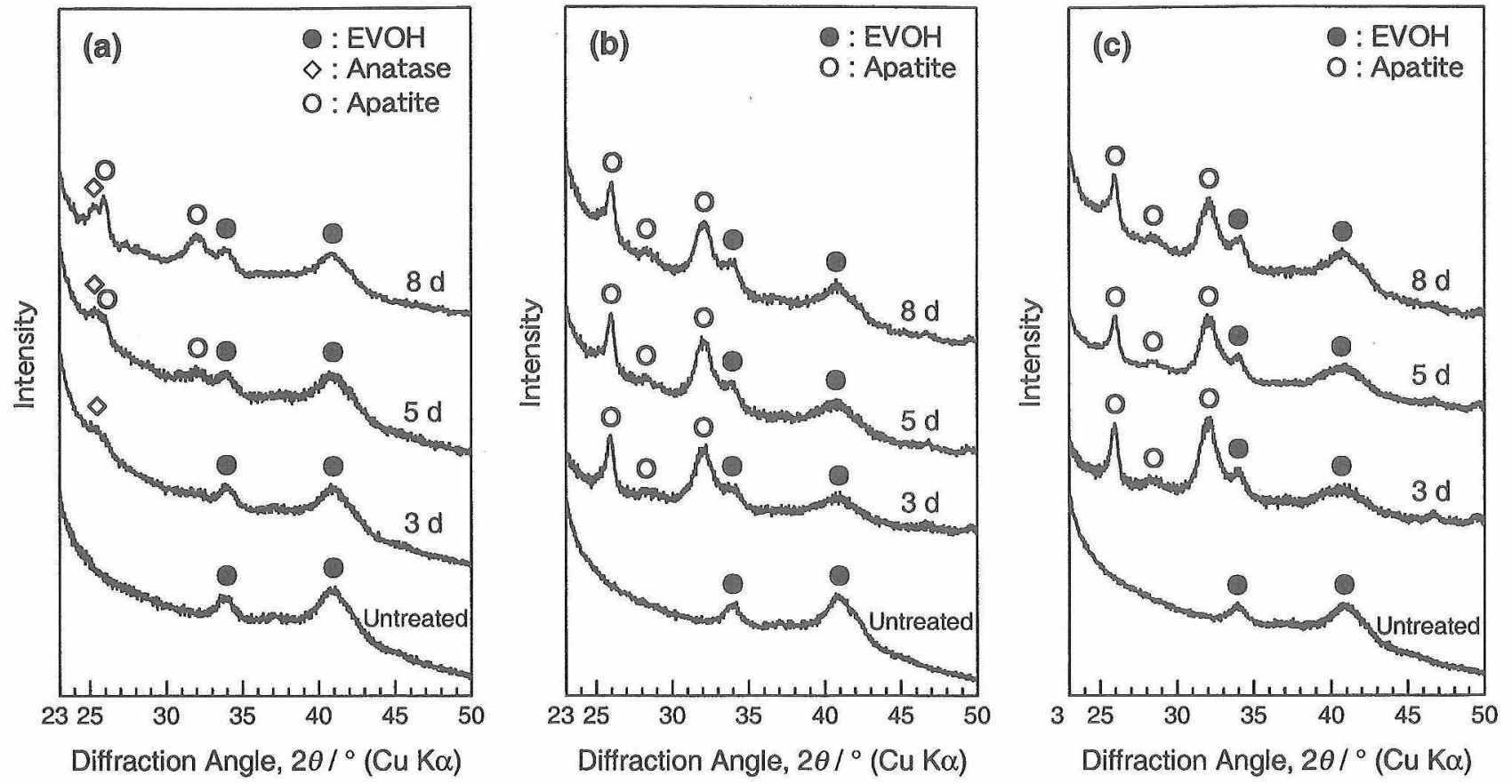

Fig. 5. TF-XRD patterns of surfaces of the EIHT plates, untreated and treated with $0.10 \mathrm{M} H \mathrm{HCl}$ solution for various periods up to $8 \mathrm{~d}$, and subsequently soaked in SBF for $2 \mathrm{~d}(\mathrm{a}), 7 \mathrm{~d}(\mathrm{~b})$, or $14 \mathrm{~d}(\mathrm{c})$.
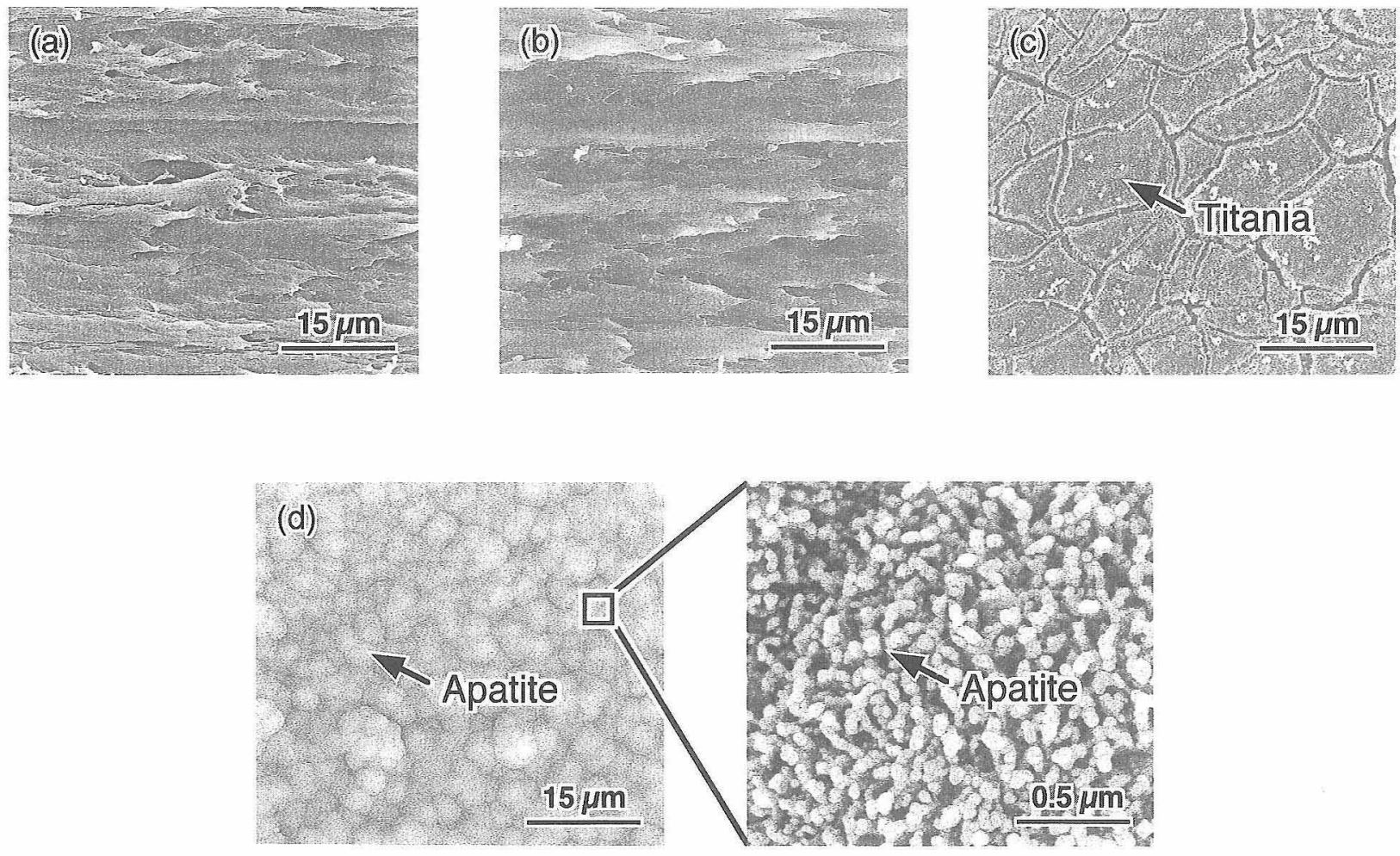

Fig. 6. FE-SEM photographs of surfaces of the plates of EVOH (a), EIH (b), EIHT treated with $0.10 \mathrm{M}$ HCl solution for $8 \mathrm{~d}$ (c), and EIHT treated with $0.10 \mathrm{M} \mathrm{HCl}$ solution for $8 \mathrm{~d}$ and then soaked in SBF for $2 \mathrm{~d}(\mathrm{~d})$.

particles with a diameter of approximately $3 \mu \mathrm{m}$ was observed on the specimen (see Fig. 6(d)). This layer should be apatite, as indicated from the TF-XRD result in Fig. 5. An FE-SEM photograph at higher magnification showed the nano-sized particles constituting this apatite (see Fig. 6 (d) right).

Figure 7 shows FE-SEM photographs of surfaces of the knitted yarn of fibers of EVOH (a), EIH (b), EIHT treated with $0.10 \mathrm{M} \mathrm{HCl}$ solution for $8 \mathrm{~d}$ (c), and EIHT treated with $0.10 \mathrm{M} \mathrm{HCl}$ solution for $8 \mathrm{~d}$ and then soaked in SBF for $2 \mathrm{~d}$ 

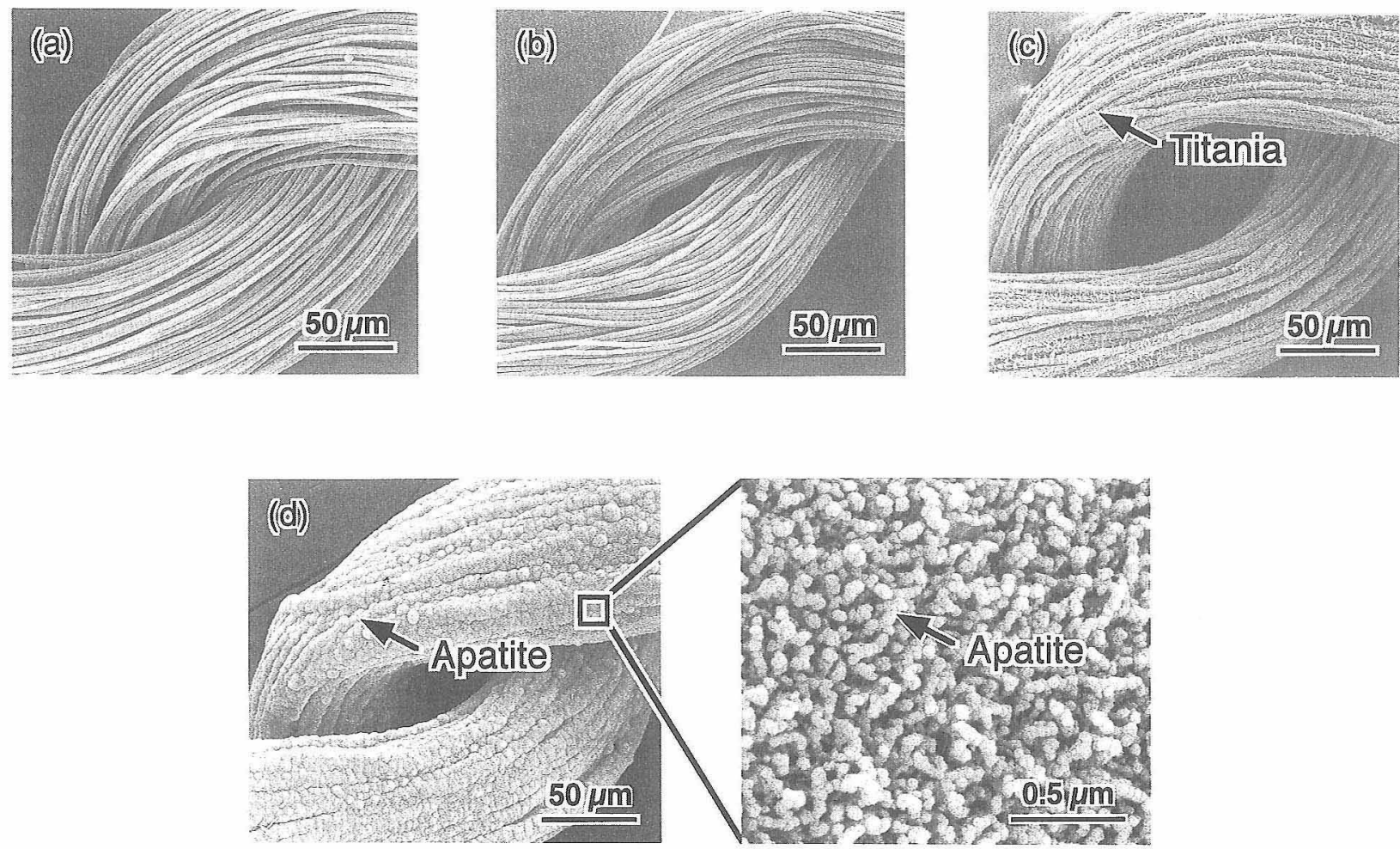

Fig. 7. FE-SEM photographs of surfaces of the knitted yarn of fibers of EVOH (a), EIH (b), and EIHT treated with $0.10 \mathrm{M} \mathrm{HCl}$ solution for $8 \mathrm{~d}(\mathrm{c})$, and EIHT treated with $0.10 \mathrm{M} \mathrm{HCl}$ solution for $8 \mathrm{~d}$ and then soaked in SBF for $2 \mathrm{~d}(\mathrm{~d})$.

(d). The specimen changed its surface morphology in the same manner as the EVOH plate shown in Fig. 6. A dense apatite layer consisting of nano-sized particles was observed on the surface of the specimen soaked in SBF for $2 \mathrm{~d}$ (see Fig. $7(\mathrm{~d}))$.

\section{Discussion}

It was found from the results obtained in the present study that the apatite-forming ability of surface-modified EVOH was significantly dependent on the $\mathrm{HCl}$ concentration and period of treatment with $\mathrm{HCl}$ solutions for the EIHT plate. As shown in Fig. 3, both the untreated EIHT plate and the EIHT plate treated with ultra-pure water did not form apatite on their surfaces in SBF, even after $14 \mathrm{~d}$. This might be attributed to a small number of Ti-OH groups on the specimen because of remaining unhydrolyzed alkoxy groups, and the amorphous structure of the titania layer on the specimen, which is not effective in inducing apatite nucleation. ${ }^{24)}$ The former is supported by the XPS result (see Fig. 2(a)), and the latter is supported by the TF-XRD result (see Fig. 2 (b)) .

The EIHT plate treated with $1.00 \mathrm{M} \mathrm{HCl}$ solution also formed no apatite on its surface in SBF even after $14 \mathrm{~d}$, as shown in Fig. 3. This can be explained as follows. The titania layer that formed on the EIHT plate was originally an amorphous layer containing a large number of alkoxy groups. It is thought that such a layer is unstable, and hence easily dissolved into $1.00 \mathrm{M} \mathrm{HCl}$ solution during the $\mathrm{HCl}$ solution treatment. This was confirmed by the observation that the surface composition of the specimen treated with $1.00 \mathrm{M} \mathrm{HCl}$ solution was quite similar to that of the EIH plate, i.e., the specimen as treated with IPTS before the titania solution treatment (see Fig. 1(a) and Fig. 2(a)). The $\mathrm{Si}-\mathrm{OH}$ groups remaining on the specimen after the $\mathrm{HCl}$ solution treatment are not effective for apatite nucleation in
SBF. ${ }^{8), 13)}$

In contrast, the EIHT plate treated with $0.01 \mathrm{M} \mathrm{HCl}$ solution for $5 \mathrm{~d}$, and the EIHT plate treated with $0.10 \mathrm{M} \mathrm{HCl} \mathrm{so-}$ lution for 3,5 or $8 \mathrm{~d}$, formed apatite on their surfaces in SBF within $14 \mathrm{~d}$, as shown in Figs. 3, 5 and 6. The apatite-forming ability of the specimen was improved with increasing $\mathrm{HCl}$ concentration up to $0.10 \mathrm{M}$ in the $\mathrm{HCl}$ solution treatment (see Fig. 3) and increasing period of the treatment up to $8 \mathrm{~d}$ (see Fig. 5). This is explained as follows. During the $\mathrm{HCl}$ solution treatment, the titania layer, formed on the specimen by the titania solution treatment, transforms its structure from amorphous to anatase, through hydrolysis of alkoxy groups existing in the titania layer into $\mathrm{Ti}-\mathrm{OH}$ groups, and subsequent condensation of the $\mathrm{Ti}-\mathrm{OH}$ groups to form a Ti-O-Ti network. This hypothesis is supported by the XPS and TF-XRD results shown in Figs. 2 and 4. The $\mathrm{HCl}$ catalyzes hydrolysis of alkoxy groups to form many Ti-OH groups and promotes the transformation of amorphous titania into anatase. Ti-OH groups have been believed to be effective in inducing apatite nucleation in SBF, from the experimental fact that a titania gel with an anatase structure rich in $\mathrm{Ti}-\mathrm{OH}$ groups forms apatite on its surface in SBF, whereas an anatase single crystal with little Ti-OH groups does not. ${ }^{31)}$ However, all kinds of $\mathrm{Ti}-\mathrm{OH}$ groups are not equally effective in inducing apatite nucleation. The $\mathrm{Ti}-\mathrm{OH}$ groups in an anatase structure are more effective in inducing apatite nucleation than those in amorphous structure. ${ }^{24)}$ Therefore, both the increase in number of $\mathrm{Ti}-\mathrm{OH}$ groups and the transformation of the titania from amorphous into anatase on the specimen, caused by the increase in $\mathrm{HCl}$ concentration and period in the $\mathrm{HCl}$ solution treatment, are responsible for the improvement of the apatite-forming ability of the specimen. Once the apatite nuclei are formed, they grow spontaneously by consuming calcium and phosphate ions from SBF, since the SBF is 
highly supersaturated with respect to apatite. ${ }^{32}$

The EIHT plate, which was treated with $0.10 \mathrm{M} \mathrm{HCl} \mathrm{so-}$ lution for $8 \mathrm{~d}$, showed the best apatite-forming ability among all of the examined specimens. In fact, a dense layer consisting of apatite nanocrystals was successfully formed on the EIHT plate, which was treated with $0.10 \mathrm{M} \mathrm{HCl}$ solution for $8 \mathrm{~d}$ and then soaked in SBF for $2 \mathrm{~d}$ (Fig. 6(d)). The apatite layer formed on this plate adhered to the specimen surface so strongly that the apatite layer was not peeled off from the surface of the specimen, even by a tape-detaching test using Scotch ${ }^{\circledR}$ tape. The same kind of nanoapatite layer was successfully formed even on the surface of individual EVOH fiber constituting the knitted yarn, which was surface-modified and soaked in SBF for 2 d (Fig. 7 (d)). This composite structure is similar to that of natural bone, in which apatite nanocrystals are deposited on fine organic collagen fibers. ${ }^{1)}$ Therefore, if the present surface modification can be applied to a three-dimensional fabric with a structure similar to that of the collagen fibers in natural bone, a nanoapatite-organic polymer fiber composite with an analogous structure to that of natural bone could be obtained. The resultant composite could have great potential as a bone substitute, since it is expected to exhibit mechanical properties analogous to those of natural bone, ${ }^{2)}$ as well as high bone-bonding ability through a bonelike apatite layer on its surface. ${ }^{3), 4)}$

\section{Conclusion}

Bonelike apatite was successfully formed on a knitted yarn of EVOH fibers as well as on an EVOH plate in SBF at $36.5^{\circ} \mathrm{C}$ within only $2 \mathrm{~d}$, when the surface of the EVOH was previously modified with $\mathrm{Ti}-\mathrm{OH}$ groups with an anatase structure. The present surface modification of EVOH would be useful for obtaining a nanoapatite-organic polymer fiber composite with an analogous structure to that of natural bone. The resultant composite could be a new bone substitute with mechanical properties and bone-bonding ability analogous to those of natural bone.

Acknowledgements This work is in part supported by the R \& D Projects in "Advanced Support System for Endoscopic and Other Minimally Invasive Surgery" entrusted from the New Energy and Industrial Technology Development Organization (NEDO) to the Japan Fine Ceramics Center. Ayako Oyane is grateful for a Grant-in-Aid for Scientific Research for Young Scientists from the Ministry of Education, Culture, Sports, Science and Technology, Japan.

\section{References}

1) Park, J. B. and Lakes, R. S., "Biomaterials," 2nd ed., Plenum Publishing, New York (1992) p. 194

2) Kokubo, T., Anales de Quimica, Int. Ed., 93, S49-55 (1997).

3) Kokubo, T., Biomaterials, 12, 155-63 (1991).

4) Tanahashi, M., Kokubo, T., Nakamura, T., Katsura, Y. and Nagano, M., Biomaterials, 17, 47-51 (1996).

5) Tanahashi, M., Yao, T., Kokubo, T., Minoda, M., Miyamoto, T., Nakamura, T. and Yamamuro, T., J. Am. Ceram. Soc., 77, 2805-08 (1994).

6) Taguchi, T., Kishida, A. and Akashi, M., Chem. Lett., 8, 711-12 (1998)

7) Shikinami, Y. and Kawarada, H., Biomaterials, 19, 617-35 (1998).

8) Oyane, A., Minoda, M., Miyamoto, T., Takahashi, R., Nakanishi, K., Kim, H.-M., Kokubo, T. and Nakamura, T., J. Biomed. Mater. Res., 47, 367-73 (1999).
9) LeGeros, R. Z. and LeGeros, J. P., "An Introduction to Bioceramics," Ed. by Hench, L. L. and Wilson, J., World Scientific Publishing Co., Pte., Singapore (1993) pp. 139-80.

10) Oonishi, H., Hench, L. L., Wilson, J., Sugihara, F., Tsuji, E. Matsuura, M., Kin, S. and 'Yamamoto, T., J. Biomed. Mater. Res., 51, 37-46 (2000).

11) Kokubo, T., Kushitani, H., Sakka, S., Kitsugi, T. and Yamamuro, T., J. Biomed. Mater. Res., 24, 723-34 (1990).

12) Gamble, J. L., "Chemical Anatomy, Physiology and Pathology of Extracellular Fluid," 6th ed., Harvard University Press, Cambridge (1967)

13) Oyane, A., Minoda, M., Miyamoto, T., Nakanishi, K., Kawashita, M., Kokubo, T. and Nakamura, T., "Bioceramics," Vol. 13, Ed. by Giannini, S. and Moroni, A., Trans Tech Publications, Switzerland (2000) pp. 713-16.

14) Oyane, A., Minoda, M., Miyamoto, T., Nakanishi, K., Kawashita, M., Kokubo, T. and Nakamura, T., "Materials Science for the 21st Century," Vol. B, Ed. by Miyata, N., Ota, R., Miyamoto, Y. and Shiono, T., Soc. Mater. Sci., Japan (2001) pp. 75-78.

15) Li, P., Ohtsuki, C., Kokubo, T., Nakanishi, K., Soga, N., Nakamura, T. and Yamamuro, T., J. Am. Ceram. Soc., 75, 2094-97 (1992).

16) Li, P., Ohtsuki, C., Kokubo, T., Nakanishi, K., Soga, N., Nakamura, T. and Yamamuro, T., J. Mater. Sci.: Mater. Med., 4, 127-31 (1993).

17) Li, P., Kokubo, T., Nakanishi, K. and de Groot, K., Biomaterials, 14, 963-68 (1993).

18) Cho, S. B., Kokubo, T., Nakanishi, K., Soga, N., Ohtsuki, C., Nakamura, T., Kitsugi, T. and Yamamuro, T., J. Am. Ceram. Soc., 78, 1769-74 (1995).

19) Cho, S. B., Nakanishi, K., Kokubo, T., Soga, N., Ohtsuki, C. and Nakamura, T., J. Biomed. Mater. Res. Appl. Biomater., 33, 145-51 (1996).

20) Cho, S. B., Miyaji, F., Kokubo, T., Nakanishi, K., Soga, N. and Nakamura, T., J. Mater. Sci.: Mater. Med., 9, 279-84 (1998).

21) Yamashita, S., Nagata, S. and Takakura, K., Kobunshi Ronbunshu, 36, 257-64 (1979) [in Japanese].

22) Li, P., Ohtsuki, C., Kokubo, T., Nakanishi, K., Soga, N. and de Groot, K., J. Biomed. Mater. Res., 28, 7-15 (1994).

23) Li, P., Kangasniemi, I., de Groot, K. and Kokubo, T., J. Am. Ceram. Soc., 77, 1307-12 (1994).

24) Uchida, M., Kim, H.-M., Kokubo, T. and Nakamura, T., "Bioceramics," Vol. 12, Ed. by Ohgushi, H., Hasting, G. W. and Yoshikawa, T., World Scientific Publishing Co., Pte., Singapore (1999) pp. 149-52.

25) Miyazaki, T., Kim, H.-M., Miyaji, F., Kokubo, T., Kato, H. and Nakamura, T., J. Biomed. Mater. Res., 50, 35-42 (2000).

26) Miyazaki, T., Kim, H.-M., Kokubo, T., Kato, H., Nakamura, T. and Ohtsuki, C., "Bioceramics," Vol. 13, Ed. by Giannini, S. and Moroni, A., Trans Tech Publications, Switzerland (2000) pp. 43-46.

27) Uchida, M., Kim, H.-M., Miyaji, F., Kokubo, T. and Nakamura, T., "Bioceramics," Vol. 11, Ed. by LeGeros, R. Z. and LeGeros, J. P., World Scientific Publishing Co., Pte., Singapore (1998) pp. 77-80.

28) Kokubo, T., Takagi, H. and Tashiro, M., J. Non-Cryst. Solids, 52, 427-33 (1982)

29) Cho, S. B., Kokubo, T., Nakanishi, K., Soga, N., Ohtsuki, C., Nakamura, T., Kitsugi T. and Yamamuro, T., J. Am. Ceram. Soc., 78, 1769-74 (1995).

30) Wen, J. and Wilkes, G. L., Polym. Bull., 37, 51-57 (1996).

31) Li, P., Ohtsuki, C., Kokubo T., Nakanishi, K., Soga N. and de Groot, K., J. Biomed. Mater. Res., 28, 7-15 (1994).

32) Ohtsuki, C., Kokubo, T. and Yamamuro, T., J. Non-Cryst. Solids, 143, 84-92 (1992). 